\title{
Management and Employee Perceptions of Fuel Conservation Programs within a U.S. Supplemental Air Carrier
}

\author{
Jack E. Troutt III, Timm J. Bliss, and Chad L. Depperschmidt \\ Oklahoma State University
}

\begin{abstract}
As fuel prices continue to remain a major cost factor to air carriers around the world, steps must be taken in order to reduce the amount of jet fuel that a carrier utilizes on a daily basis. Air carriers; therefore, must try to maximize any fuel conservation program that they might have. In order to do this, a better understanding of employee perceptions with regards to these types of programs would be beneficial. The purpose of this study was to understand the perceptions that employee groups (operation and maintenance) have about fuel conservation programs utilizing a mixed method approach. A Likert scale based series of questions that was distributed in an anonymous survey gathered quantitative data, while a series of open ended questions gathered qualitative data during the completion of the same survey. Additionally a series of open ended questions was also asked of several members of a fuel conservation committee. Four research questions were identified and utilized in order to better guide the findings of the study using various statistical techniques. This study found that; generally management employees had a positive perception of fuel conservation programs, non-management employees had a slightly less positive perception about the programs, and there was no discernible difference between maintenance and operation employee's perceptions. Additionally, several trends were identified that indicated their importance in this fuel conservation program: data, ideas, communication, trust and incentive.
\end{abstract}

\section{Introduction}

In the summer of 2008, the world economy saw unprecedented challenges to growth and prosperity. Market indexes took substantial hits in terms of value from such pressures as the housing crisis, bankruptcy of several large scale financial firms, and the drop in demand for consumer goods. The largest challenge, however, was the meteoric rise of the cost of unrefined oil, and equally, the cost of oil derived fuel (Energy, 2009). For their part, companies that are vulnerable to rises in energy costs saw immense pressure from these rises in prices. Air carriers were particularly sensitive to fuel costs and the effect those costs had to their bottom line. Jet fuel prices can consume up to $30 \%$ of an air carrier's operating costs, so any increase in the raw cost of fuel puts negative pressure on an air carrier's profitability (Energy, 2012).

Logically, the focus was turned towards strategic ways that air carriers could actually decrease fuel usage. Just as a person might try various things to get the most out of a tank 
of gas for their car, air carriers tried to maximize their fuel by looking at ways of reducing their fuel consumption (United Parcel Service, 2013). While it may hold true that most air carriers had some sort of fuel conservation programs in place before the summer of 2008, these programs took on new importance in the high cost for oil environment that air carriers found themselves in.

The issue that arises with fuel conservation programs is that they depend on the full participation of the personnel required to implement the programs on a daily basis in order to maximize effectiveness and gain the most savings for the carrier. Airline employees must perceive that any fuel conservation program is in their best interest as well as in the best interest of the airline in order to fully participate in the program. If employees perceive the benefit of a fuel conservation program, they are more likely to be more dedicated to its functions ensuring a higher level of effectiveness. Companies have been concerned about the attitudes and perceptions of their employees for decades as exhibited in the Hawthorne Studies at Western Electric (J. Wilensky; H. Wilensky 1951). Other studies such as those by Victor Vroom have found that if workers do not want to participate in a program due to psychological factors such as worker's attitudes and expectations then the programs would suffer (Sashkin, 1984). Studies also indicate that job attitudes and participation are related in decision making in regards to workplace programs (Cotton, Vollrath, Froggatt, Lengnick-Hall, Jennings, 1988).

The purpose of this study was to identify the perceptions of fuel conservation programs among airline operation and maintenance employees directly tasked with completing daily performance activities that impact fuel conservation programs. Additionally, the perceptions of airline management supervising fuel conservation programs were also identified in this study. Identifying the perceptions by both air carrier employees and managers regarding their fuel conservation programs can lead to efforts to make fuel conservation programs more efficient and successful by identifying underlining differences and negative perceptions. In addition, corrective steps could be implemented to ensure the efficiencies of the fuel conservation program are maintained daily by all airline personnel directly involved in the program.

\section{Research Methodology}

The study utilized a mixed method methodology that was delivered in the form of an anonymous survey and a series of interview questions. The mixed method style of research enables narratives to be added to studies that traditionally have only had quantitative data, giving a greater picture of the studied subject (Hesser-Biber, 2010). Furthermore, mixed method research considers "multiple viewpoints, perspectives, positions, and standpoints" when trying to understand the subject being studied (Johnson, Onwuegbuzie, Turner, 2007). In a survey-type instrument, a mixed method study can accurately illustrate both qualitative and quantitative study by using techniques such as a series of Likert statements and open ended questions. The Likert statements can establish a quantity to any perceptions that employees might have about a fuel conservation program, while a series of open ended 
questions can establish a qualitative narrative in which a subject can better illustrate their feelings on such programs. Once developed, the survey was distributed to operation and maintenance personnel and their supervising managers at an Oklahoma-based air carrier. Additionally, a series of four interview questions were administered to several members of the fuel conservation program's oversight committee at the same air carrier. The oversight committee were not administered the survey. The interview questions were designed to illustrate the team members' perceptions of what a fuel conservation program is comprised of while also gaining their perception on several additional aspects of conservation programs such as employee engagement. A trend analysis was conducted on these questions to identify and better understand the reoccurring themes regarding the individual perceptions of fuel conservation programs.

\section{Population and Sample}

The air carrier chosen for this investigation is a non-scheduled aircraft charter company based in Oklahoma. Major business partners that charter aircraft from the company include governmental agencies, other scheduled air carriers that are in need of additional aircraft and service within their own operations, or private charters such as large groups of businesses or sports personnel. This unique type of flying prevents a long term forecast of business; therefore costs must be kept to a minimum in order for the company to remain profitable. Thus, a fuel conservation program is vital in order to remain competitive in contract bidding and also to reduce overall expenses of operation.

The premise for this study was developed at the beginning of this air carriers' fuel conservation program. At the start of 2013, the carrier decided to establish a fuel conservation program at the behest of one of its long-time contracts. At the same time, an oversight committee was created to oversee the fuel conservation program. Initial program implementation within the employee groups began in February 2013. The study was conducted during the June and July 2013 timeframe, approximately six months after the initial dissemination of the fuel conservation program at the airline. Permission to perform this research study was approved by the Institutional Review Board at Oklahoma State University (IRB application number: ED1319).

The sample population for this study included the entire group of pilots and mechanics, including managers, employed at the air carrier. Additionally, members of the fuel conservation committee were interviewed to understand the perceptions of individuals that were in charge of making strategic decisions for the company's program.

The following research questions set the basis for determining the perceptions about fuel conservation programs within this air carrier.

Research Question 1: What is the perception of fuel conservation programs with regards to airline management (managers) tasked with program implementation? 
Research Question 2: What is the perception of fuel conservation programs among airline operation and maintenance personnel directly tasked with completing daily performance activities that impact fuel conservation programs?

Research Question 3: What are the differences, if any, between the perceptions of airline management and the operation and maintenance employees?

Research Question 4: What is the perception of fuel conservation programs among members of the fuel conservation oversight committee?

\section{Research Instrument}

The population for the research instrument was operation and maintenance employees and their managers within the air carrier based in Oklahoma. Electronic mail (e-mail) was sent to all potential participants utilizing company e-mail addresses. Within this e-mail was a link to a web site that housed the survey along with a password that the participants needed to access the survey. The link contained in the e-mail was anonymous, so no identifying information was collected about the participant or the computer that was utilized to take the survey. The population group for the survey consisted of 263 employees that included all operation and maintenance employees directly related to the airline's fuel conservation program.

\section{Interview Instrument}

The population sample selected for the interview portion of the study was members of the fuel conservation oversight committee. A total of eight individuals were purposely selected by the researchers for their diverse professional backgrounds and assigned responsibilities for the air carrier; including finance, maintenance, operation, pilots, training, and executive management.

\section{Reliability and Validity}

The Likert-scale statements listed in the research instrument were analyzed for reliability by using Cronbach's alpha. Cronbach's alpha is a general formula for estimating internal consistency based on a determination of how all items on a test to all other items and to the total test (Gay, Mills, \& Airasian, 2006). George and Mallery (2003) have established the following Cronbach's alpha acceptance scale: " - > .9 - Excellent, - > .8 Good, - > .7 - Acceptable, - > .6 - Questionable, - > .5 - Poor, and - $<.5$ - Unacceptable" (p. 231). An alpha coefficient is generally regarded as one of the most used scales of reliability due to its ease of interpretation and objectiveness (Yang \& Green, 2011). Calculated alpha's approach 1 as the reliability increases, with .8 or higher being regarded a good value for the alpha (Peterson, 1994). Cronbach \& Meehl (1955) states that "content validity is established by showing that the test items are a sample of a universe in which the investigator is interested" (p. 282). 
Content validity for the Likert-scale statements was assured by forwarding the survey to several aviation/airline professionals for review. These suggestions were incorporated into the final research instrument.

\section{Presentation of Data and Analysis}

Data for the survey instrument was collected utilizing the Qualtrics system of on-line survey software. This software enabled e-mails to be sent to all potential participants at the airline. E-mails were sent to the complete group of 185 pilots (operation) and 78 mechanics (maintenance) employed by the air carrier for a total of 263 potential participants. Of these potential participants, 53 followed the link to the research instrument. One person did not agree to the information disclosure at the start of the survey; resulting in 52 completed responses and a $20 \%$ response rate (Table 1). This response rate, while possibly not providing the definitive answers that other air carriers might desire, provided enough information to offer generalized statements and judgments regarding any current or future fuel conservation program.

Table 1

Summary of Response Rates

\begin{tabular}{lccc}
\hline Department & $\begin{array}{c}\text { Potential } \\
\text { Participants }\end{array}$ & Actual Responses & Response Rate \\
\hline Maintenance & 78 & 17 & $22 \%$ \\
Operation & 185 & 35 & $19 \%$ \\
Total & 263 & 52 & $20 \%$ \\
\hline
\end{tabular}

The first demographic question contained in the survey asked the participants to list their position within the airline. The second demographic question asked participants to identify which department (operation or maintenance) they worked for within the airline. Of the fifty-two participating respondents, the majority indicated that they worked in the operation department $(76 \%, \mathrm{~N}=35)$ and the remaining participants indicated that they worked in the maintenance department $(33 \%, \mathrm{~N}=17)$. The third demographic question asked participants if they held a management position within the airline. Only thirteen percent $(13 \%, N=7)$ of the total participants indicated they were managers. The next demographic question asked the participants how long they have been employed at the airline. Twenty participants $(38.5 \%, \mathrm{~N}=20)$ indicated they had been employed less than five years. The majority of participants $(44.2 \%, \mathrm{~N}=23)$ indicated they had worked at the air carrier between five and ten years and a smaller percentage $(17.3 \%, \mathrm{~N}=9)$ indicated that they had worked at the air carrier for over eleven years. The maximum time that an employee had worked at the air carrier was fifteen years. The final demographic question asked participants to indicate the total number of years they have been employed in the air carrier industry. The smallest percentage of participants $(19.2 \%, \mathrm{~N}=10)$ indicated that they 
had less than ten total years of experience in the air carrier industry; whereas, $30.8 \%$ $(\mathrm{N}=16)$ indicated they had between ten to twenty years of experience. The largest percentage of respondents indicated they had twenty one years or more of industry experience $(50 \%, \mathrm{~N}=26)$.

\section{Survey Likert Scale Responses}

A total of 11 Likert scale statements were presented to the participants (Table 2).

\section{Analysis of Likert Statements}

Regarding the Likert statements, the Cronbach's alpha was analyzed using the IBM SPSS software. Using data results from all participants, the reliability of the instrument was found to have an alpha coefficient of .807. According to George and Mallery (2003), the internal reliability of the instrument would be rated good. To better understand the relationship between the department variable and the Likert statements, a Pearsons correlation was computed utilizing the SPSS statistical software. Only one Likert statement, statement 10, exhibited a significant correlation between the variables. When the Likert Statements were correlated with the management variables utilizing the SPSS software, there was a significant correlation with 6 of the 11 Likert statements.

\section{Survey Open Ended Question Responses}

Question 1: On a daily basis, what job functions do you perform that are directly related to your airline's fuel conservation program?

By asking the participants what daily activities they perform that can impact their fuel conservation program, several threads developed as far as the perceived importance regarding fuel conservation. The management employees (managers) were generally more elaborate as responses included "data analysis and communication," "overseeing mission planning and aircraft schedules," "engine run and taxi operations," and "development of all training curricula, elements, and courseware for all pilots, flight attendants, and dispatchers." Responses from the managers were also more specific. Non-management participants were more simplistic in their responses. $18 \%(\mathrm{~N}=8)$ of non-management participants indicated they operated some form of equipment, including the aircraft. 
Table 2

Summary of Likert Statement Responses

\begin{tabular}{|c|c|c|c|c|c|c|}
\hline & Likert Statement & $\begin{array}{c}\text { Strongly } \\
\text { Disagreed }\end{array}$ & Disagreed & Agreed & $\begin{array}{c}\text { Strongly } \\
\text { Agreed }\end{array}$ & Total \\
\hline 1 & $\begin{array}{l}\text { I am aware of my airlines fuel } \\
\text { conservation program. }\end{array}$ & 0 & 4 & 23 & 25 & 52 \\
\hline 2 & $\begin{array}{l}\text { A fuel conservation program is } \\
\text { important to my airline. }\end{array}$ & 1 & 1 & 25 & 25 & 52 \\
\hline 3 & $\begin{array}{l}\text { My airline's fuel conservation program } \\
\text { is important to me. }\end{array}$ & 1 & 4 & 28 & 19 & 52 \\
\hline 4 & $\begin{array}{l}\text { It is important that I consider fuel } \\
\text { conservation strategies' when } \\
\text { performing my daily job functions. }\end{array}$ & 0 & 4 & 29 & 19 & 52 \\
\hline 5 & $\begin{array}{l}\text { My perceptions (attitudes, mental } \\
\text { image) about my airline's fuel } \\
\text { conservation programs should be very } \\
\text { important to the executive } \\
\text { management team. }\end{array}$ & 0 & 2 & 24 & 26 & 52 \\
\hline 6 & $\begin{array}{l}\text { It is important that all employees are } \\
\text { adequately involved with any fuel } \\
\text { conservation program. }\end{array}$ & 1 & 4 & 20 & 27 & 52 \\
\hline 7 & $\begin{array}{l}\text { My airline sought my professional } \\
\text { input in the creation of its fuel } \\
\text { conservation program. }\end{array}$ & 14 & 17 & 12 & 9 & 52 \\
\hline 8 & $\begin{array}{l}\text { My airline utilized my input in the } \\
\text { creation of any fuel conservation } \\
\text { program. }\end{array}$ & 20 & 18 & 9 & 5 & 52 \\
\hline 9 & $\begin{array}{l}\text { Given an opportunity, my airline } \\
\text { should listen to any new input I } \\
\text { provide about my airline's fuel } \\
\text { conservation program. }\end{array}$ & 0 & 5 & 26 & 21 & 52 \\
\hline 10 & $\begin{array}{l}\text { Airline employees' continued input } \\
\text { regarding an existing fuel } \\
\text { conservation program is important to } \\
\text { my airline. }\end{array}$ & 7 & 9 & 19 & 17 & 52 \\
\hline 11 & $\begin{array}{l}\text { Over time, the fuel conservation } \\
\text { program at my airline will positively } \\
\text { impact my financial future (profit } \\
\text { sharing, wage increase, stock price). }\end{array}$ & 23 & 8 & 13 & 8 & 52 \\
\hline
\end{tabular}


Question 2: As an employee, do you feel that you are adequately involved in your airline's fuel conservation program? Why or why not?

This question focused more directly on a participant's perceived importance regarding the air carrier's fuel conservation program. Although they were not prompted to do so, most participants replied to the first part of the question either with a yes or no response, and then elaborated on why they indicated as such. In response to this question, $85 \%(\mathrm{~N}=6)$ of management participants indicated that were adequately involved in the fuel conservation program. Non-management participants' results for this question were more varied than the management participants. However, 53\% $(\mathrm{N}=24)$ of non-management participants did not respond favorably to the question. Several negative responses tried to give logical reasoning for their perceived non-involvement with responses that included "no because of time constraints." Responses also indicated a lack of trust between those in management positions and those operating the equipment.

Question 3: If given the opportunity, what fuel conservation ideas would you bring to the company's attention to improve your airline's overall fuel conservation program?

This question sought fuel conservation ideas that the participants perceived could be brought to the air carrier's attention. Management employees indicated several ideas. Two of the managers indicated that better tracking of the data was needed by responding "better tracking of fuel use," and "find a way to improve the quality and accuracy of the data that is being used to make decisions." Two other management participants indicated that better ground equipment should be made available, stating "better supply and use of ground power units and $\mathrm{AC}$ units," and "AC carts and heat carts for the airplanes are mostly junk everywhere you go." Non-management participants were varied in their responses. Several agreed with management participants on the usage of ground power instead of aircraft systems. Other statements suggested practices such as reducing weight and better flight planning through techniques such as "better attention to efficient routings; and the usage of the auxiliary power unit as an area that could be improved in order to better the fuel conservation program. Other non-management participants indicated that an incentive program would be beneficial to the air carrier's fuel conservation program, making statements such as "incentivize the program," "happy employee is an efficient employee," and "I believe to make the program really work there needs to be an incentive program in place."

Question 4: What ideas, if any, could be implemented to improve the communication and involvement between employees and management with regards to fuel conservation programs?

The final question was included to better understand the participant's perception of the relationship between management and employees at the air carrier. Among management participants, $85 \%(\mathrm{~N}=6)$ indicated that communication of some sort was needed to improve 
the relationship between them and employees. As with the management participants, communication was an important topic for non-management participants; $46 \%(\mathrm{~N}=21)$ cited communication or some form of input/feedback system in their response to this question. Responses indicating this included "discussion board on the company website," "ensure communication avenues are kept open and encouraged," and "any communication would help." However, 15\% of the non-management participants indicated that there was nothing that could be done to improve relations with the air carrier.

\section{Interview Instrument}

To gain further management insight into fuel conservation programs, a series of four interview questions were asked to membership of the air carrier's fuel conservation program committee.

\section{Question 1: What constitutes (procedures/processes) an effective fuel conservation program?}

Most participants initially indicated in their response that what is commonly referred to as "buy in" among the employee groups was the most important part of an effective fuel conservation program. Two other committee members suggested that having a dataoriented program would be the most important process; one stating, "if you don't know what you are looking at, you don't know where to go."

Question 2: What are the benefits of a fuel conservation program?

Every participant that was interviewed cited some sort of "financial savings" when it comes to the benefit of a fuel conservation program. Several participants also cited the weight savings on carrying less fuel, which in turn meant the air carrier, could carry additional revenue generating payloads. Another mentioned benefit was that the equipment on the aircraft would be used less and at a lower intensity; thus saving the air carrier money regarding maintenance costs.

Question 3: What are obstacles to a fuel conservation program?

As the previous question dealt with the benefits, it was necessary to also investigate the obstacles. Again, several participants indicated that "buy-in" from the various employee groups was one of the biggest obstacles to a fuel conservation program. Other obstacles included ensuring that the data being collected is accurate, as one participant stated, "majority of the obstacles are making a determination of what your baseline is." 


\section{Question 4: How important is employee engagement to an airline's overall strategy regarding a fuel conservation program?}

Committee responses included: "it's paramount," "if the workforce is not engaged and supportive of the program, the program will not be successful," and "the more people that are on board with it, the better the chances are that it is going to be successful."

\section{Findings}

When the data for the Likert statements between maintenance and operation employees was separated, the results were similar for both groups. After the Likert statements were transferred into an ordinal series, any mean greater than 2.5 indicated that more individuals agree with the statement than disagree. For both groups, the mean for most statements was over 3.0; indicating both operation and maintenance employees agreed with the statements.

Notable exceptions to the mean value, greater than 2.5 , were the statements "my airline sought my professional input in the creation of any fuel conservation program" (maintenance mea $=2.35$, operation mean $=2.29$ ), "my airline utilized my input in the creation of any fuel conservation program" (maintenance mean $=2.12$, operation mean $=$ 1.91 ), and "over time, the fuel conservation program at my airline will positively impact my financial future (profit sharing, wage increase, stock price)" (maintenance mean $=2.47$, operation mean $=1.94$ ). Another notable result was the difference in means between the maintenance and operation employees with regards to statement 10, "airline employees' continued input regarding an existing fuel conservation program is important to my airline." The mean of the operation employees' responses was only 2.69 for this statement, while maintenance employees generally agreed with the statement with a mean of 3.29.

When the Likert data was further differentiated between management and nonmanagement employees, a few more differences emerged. Management participants generally agreed with all Likert statements, as the mean for all management responses was over 2.5; however, several differences emerged with the non-management employee's data. Several statements resulted in non-management responses below 2.5. These included "my airline sought my professional input in the creation of its fuel conservation program," "my airline utilized my input in the creation of any fuel conservation program," and "over time the fuel conservation program at my airline will positively impact my financial future (profit sharing, wage increase, stock price)." The mean for these statements with regards to non-management employees was $2.18,1.82$, and 1.98 respectively.

\section{Open Ended and Interview Questions}

Both survey open ended questions and the interview questions were analyzed utilizing trend techniques in order to discover any similarities within the responses. After analyzing this qualitative data, five trends emerged from the responses to both open ended questions 
and interview questions. These trends were: (1) data, (2) trust, (3) incentives, (4) ideas, and (5) communication.

The importance of data emerged as an important trend; particularly, data driven themes emerged from survey open ended questions three and four, along with interview questions one and three. Several participants identified having a data-oriented program as important with statements such as "improve the quality and accuracy of the data that is being used to make decisions", and "aircraft generated data with dispatch planning." Additionally 50\% of the interviews identified data as being a key part of a fuel conservation program.

The trend of ideas and the importance of those ideas also emerged among the open ended data and the interview data. The importance of ideas emerged from statements made in response to open ended questions two, three, and four, as well as interview questions one, three, and four. Statements from participants included, "this is an ongoing program that continues to develop and as ideas are presented they are evaluated for future implementation," as well as suggestions such as "better technology (company website to input ideas)." Interview responses also indicated that the need for ideas to be received and evaluated was extremely important.

Communication developed as one of the most prevalent trends within the data. Every open ended survey question had responses that dealt with communication. Also, interview question four had several responses that dealt with communication. A total of 17 survey responses included a direct reference to communication. However, the majority of these responses had a negative connotation with regards to overall communication at the air carrier. Interview responses were less direct with regards to communication, but the importance was stated as well.

Trust was first breached in open ended question two but was also discussed in questions two and three. The majority of responses indicating a lack of trust came from the nonmanagement employees. The importance of trust was also communicated in the interviews, but typically in a more positive format.

The final trend that emerged within both the open ended survey questions and the interviews was the concept of an intrinsic incentive. Several participants responded that an incentive would aid in the implementation of the fuel conservation program. The survey responses with regards to incentives were typically recorded in open ended question four. Interview participants' responses illustrating the trend of incentives also emphasize the importance for such motivators regarding a fuel conservation program.

\section{Results Interpretation}

Given the similarities between both the responses given in the survey, along with the data collected during the interviews; several conclusions can be drawn regarding the fuel conservation program at the air carrier with respect to the four research questions. 


\section{Research Question 1: What is the perception of fuel conservation programs with regards to airline management tasked with program implementation?}

Management responses to the survey questions in both the Likert and open ended questions were generally positive. The calculated mean for the majority of the management responses to the Likert statements was over 2.5, indicating that management participants, on average, agreed with the statements. Also, management participant responses to the open ended questions were positive, with several responses indicating adequate involvement and positive relationships with employees about the conservation program.

Research Question 2: $\quad$ What is the perception of fuel conservation programs among airline operation and maintenance personnel directly tasked with completing daily performance activities that impact fuel conservation programs?

While there were differences between both the maintenance and operation groups at the air carrier, these were comparatively small. The only Likert statement that both groups disagreed with each other with any great significance was the statement "Airline employees' continued input regarding an existing fuel conservation program is important to my airline." The mean value for this statement was still above 2.5 for both operation and maintenance employees, meaning the majority of participants still agreed with the statement. However, both groups disagreed and agreed with the other Likert statements relatively equally. This indicates that, as the majority of responses agreed with the Likert statements, the employees had a positive perception of the fuel conservation program.

\section{Research Question 3: $\quad$ What are the differences, if any, between the perceptions of airline management and the operation and maintenance employees?}

Differences between management and non-management responses were noticeable, but as with the operation and maintenance responses, three differences emerged that centered on the trends of communication, ideas, and incentive. Management participants agreed, on average, with all Likert statements, while non-management participants would disagree with the same three Likert statements that were previously mentioned. The responses collected from the open ended question established the importance of the trends of data and trust.

\section{Research Question 4: $\quad$ What is the perception of fuel conservation programs among members of the fuel conservation oversight committee?}

Research question four sought to understand the perceptions of the oversight committee in charge of the fuel conservation program. The responses from the oversight committee members were similar to statements given during the survey instrument open ended questions from both management and non-management participants. In general, all committee members expressed a positive perception of the fuel conservation program, which is logical. 


\section{Conclusion}

This study revealed that while the perceptions of the fuel conservation program at the air carrier were generally positive, there emerged five trends that any potential air carrier could focus on in order to gain the full benefit of their fuel conservation program. This result was reinforced by the interviews that were performed in conjunction with the survey. However, as the research also revealed, while all members of the fuel conservation program agreed on several aspects such as the trends mentioned previously, if a carrier fails to listen and implement those practices that maximize these trends, then the fuel program cannot operate as effectively and efficiently.

Air carriers will need to understand that it is not enough to simply implement a plan for fuel conservation and then do nothing else for the program, and expect that the program will operate efficiently. While it is true that most employees will perform their job functions as instructed, employees must be engaged in order to maximize any action asked of them. The data results provided in this study indicated that the concepts of data, ideas, communication, trust, and incentives must all be utilized to better involve employees within the air carrier's fuel conservation program.

In the end though, it is the amount of desire to save fuel that will drive a carrier's fuel conservation program implementation. A carrier will have to be properly motivated at the management level to implement the program, and will have to transfer that motivation to its various employee groups. If this motivation is missing from either the management or employees to fully implement the program, then any air carrier's fuel conservation program will suffer as a result.

\section{Implications and Recommendations}

The potential benefits from this study include the ability to tailor fuel conservation programs to better maximize employee participation and improve perceptions of the program. As noted in this study, while there was a general positive attitude towards the fuel conservation program, there were still areas of improvement. These areas of improvement could fall along the five trends of data, ideas, communication, trust, and incentives as identified in the results of this research study.

As the air carrier industry continues to deal with higher fuel prices, and the constant concern for further fuel price increases; steps must be made to maximize any fuel savings that an established fuel conservation program can provide to the carrier. Additionally, if an air carrier is thinking about establishing a fuel conservation program, attention should be given to these five trends before presenting their program to the employee groups that will be tasked to implement the program.

Based on the results of this study, the following recommendations are suggested for action. In order for air carriers to implement the most effective fuel conservation program, 
they should attempt to maximize the amount of accurate data regarding the fuel conservation program; constantly seek, consider, and implement new ideas into the program; communicate the goals and purpose of the program to the various employee groups; build the trust of those that are implementing the program on a daily basis; and offer an incentive to those that are executing the program in order to keep a positive attitude.

For any air carrier that has a fuel conservation program already established, the carrier should attempt to understand the perceptions that the employees have regarding the program. Attention should be focused to the areas of communication, trust and incentives. The air carrier should try to foster an environment where any and all communication, even negative communication, is welcomed and considered. If the carrier is only welcoming to positive communication, the trust aspect of a fuel conservation program will suffer.

To better foster the trust aspect, as well as keeping communications open, anonymous avenues like the survey utilized in this research should be considered. If employees feel that their communication is confidential, they will be more forthcoming with their opinions and ideas. This openness will build trust in the program. Another option for building employee trust in the program is to encourage management to talk directly with the employees implementing the program. This should be done either through direct face to face communication, or if employees are in a different location than the management employees traveling to the various employee locations in order to build the trust in the employee groups so the fuel conservation program management understands the employees concerns and relays the goals and intent of the conservation program.

Finally, any air carrier that seeks to maximize their program should consider offering incentives to the employees that are implementing the program effectively. Incentives can be financial benefits such as profit sharing or related bonuses, or even the simple act of recognizing top performers within the program in a company newsletter or other widely disseminated document. When employees see and understand that the company appreciates the employee actions with regards to the fuel conservation program, the employees as a whole will understand that it is important and will hopefully implement the program to the upmost of their ability.

The scope of the study was limited to one air carrier operating within the U.S. As such, to increase the applicability to the entire population of air carriers operating within the U.S., serious consideration should be made to perform further research at other air carriers. Hopefully, any further study would include larger air carriers, as the total population for the air carrier where the study was preformed was only 263 potential participants. Surveying a major Group III carrier such as those defined by the U.S Department of Transportation would enable a better understanding of the perceptions of fuel conservation programs among the entire population of U.S. air carriers (Suissa, 2012). Additional studies at other carriers would also aid in the validation of the questions and statements utilized in the survey instrument. 
Another limitation of the study was the small sample size of the population. Only 52 individuals participated in the survey instrument for a total response rate of $20 \%$, and only eight individuals were interviewed for the additional management/oversight committee perspective. As such, the results of the study should not be considered the potential complete data set of the perceptions of the entire employee group that is involved with the fuel conservation program at this air carrier. The researchers believe a contributing factor to the low response rate could be attributed to the reluctance of employees to indicate negative perceptions of a fuel conservation program implemented by their employer. Therefore, if potential respondents to this study were not supportive of fuel conservation programs or adequately understood their importance, they may have been reluctant to participate in this study.

This study did not include any research into the actual practices and procedures of a fuel conservation program. To best understand what actual fuel conservation practices, such as flying at different altitudes or using the auxiliary power unit less, make for a more effective program, further research consideration should be given to the practices that make up any fuel conservation program in order to establish the best practices for a conservation program. Only once these practices have been documented and calculated can a fuel conservation program truly be validated as the most efficient one possible. 


\section{References}

Cotton, J.L, Vollrath, D.A., Froggatt, K.L., Lengnick-Hall, M.L., \& Jennings, K.R. (1988). Employee participation: diverse forms and different outcomes. The Academy of Management Review, 13(1), 8-22.

Cronbach, L. J., \& Meehl, P. E. (1955). Construct validity in psychological tests. Psychological Bulletin, 52(4), 281-302. doi:10.1037/h0040957

Energy Information Administration. (2009). Cushing, OK WTI spot price FOB (dollars per barrel). Retrieved from http://www.eia.doe.gov/oil_gas/petroleum/info_glance/petroleum.html

Energy Information Administration. (2012, June 13). High airline jet fuel costs prompt cost-saving measures. Retrieved from http://www.eia.gov/todayinenergy/detail.cfm?id=6670

Gay, L.R., Mills, G.E., \& Airasian, P. (2006). Educational Research: Competencies for Analysis and Applications ( $8^{\text {th }}$ Ed.). Upper Saddle River, New Jersey: Pearson Prentice Hall.

George, D., \& Mallery, P. (2003). SPSS for Windows step by step: A simple guide and reference. 11.0 update ( $4^{\text {th }}$ ed.). Boston: Allyn \& Bacon.

Hesser-Biber, S. N. (2010). Mixed method research: Merging theory with practice. New York: The Guildford Press.

Johnson, R.B., Onwuegbuzie, A. J., \& Turner, L.A. (2007). Toward a definition of mixed methods research. Journal of Mixed Methods Research, 1(2), 112-133. doi: $10.1177 / 1558689806298224$

Peterson, R.A. (1994). A meta-analysis of Cronbach's coefficient alpha. Journal of Consumer Research, 21(2), 381-391.

Sashkin, M. (1984). Participative management is an ethical imperative. Organizational Dynamics, 12 (4), 5-22.

Suissa, A.Y., (2012). Air Carrier Groupings. (BTS Publication No. 304 A). Washington, DC: Retrieved from http://www.rita.dot.gov/bts/sites/rita.dot.gov.bts/files/subject_areas/airline_inform ation/accounting_and_reporting_directives/number_304a.html 
United Parcel Service. (2013). Fuel management and conservation at the UPS Airlines. UPS Airlines. Retrieved from http://pressroom.ups.com/Fact+Sheets/Fuel+Management+and+Conservation+at+ the+UPS+Airlines

Wilensky, J.L. \& Wilensky, H.L. (1951). Personnel counseling: the Hawthorne case. American Journal of Sociology, 57(3), 265-280

Yang, Y. \& Green, S. B., (2011). Coefficient alpha: A reliability coefficient for the 21st century? Journal of Psychoeducational Assessment, 29(4), 377-392. doi: $10.1177 / 0734282911406668$ 